\title{
Wie sieht die ambulante Versorgung der Zukunft aus?
}

Die Politik fördert zentrale Versorgungsstrukturen: Im Koalitionsvertrag wurde der Ausbau Medizinischer Versorgungszentren angekündigt, im aktuellen Kabinettsentwurf zum GKV-Versorgungsstärkungsgesetz nimmt das Ansinnen konkrete Formen an. Welche Folgen sich daraus für die ambulante Versorgung und für die Zahnarztpraxis ergeben, diskutieren Experten aus Politik und Gesundheitswesen beim FVDZPresseseminar am 30. Januar 2015 in Berlin. Gäste sind unter anderem die Bundestagsabgeordnete Karin Maag (CDU), der Leiter des Instituts für Mikrodaten-Analyse (IfMDA), Dr. Thomas Drabinski, und der Bundesvorsitzende des NAV-VirchowBunds, Dr. Dirk Heinrich.
Nach der Podiumsdiskussion stehen zwei Fachvorträge auf der Tagesordnung: Der Direktor der Klinik für Zahnerhaltung, Parodontologie und Präventive Zahnheilkunde der Medizinischen Hochschule Hannover, Prof. Dr. Werner Geurtsen, wird über „Biokompatibilität von Werkstoffen in der Zahnheilkunde" sprechen. Von Prof. Dr. Dr. Ralf J. Radlanski, Direktor Orale Struktur- und Entwicklungsbiologie am Charité Campus Benjamin Franklin in Berlin, erfahren die Gäste Neues aus dem Bereich „Kieferorthopädie bei Erwachsenen". Das Presseseminar richtet sich an Journalisten der Fach- und Publikumsmedien. Einen ausführlichen Bericht zur Veranstaltung finden Sie in der März-Ausgabe des DFZ.

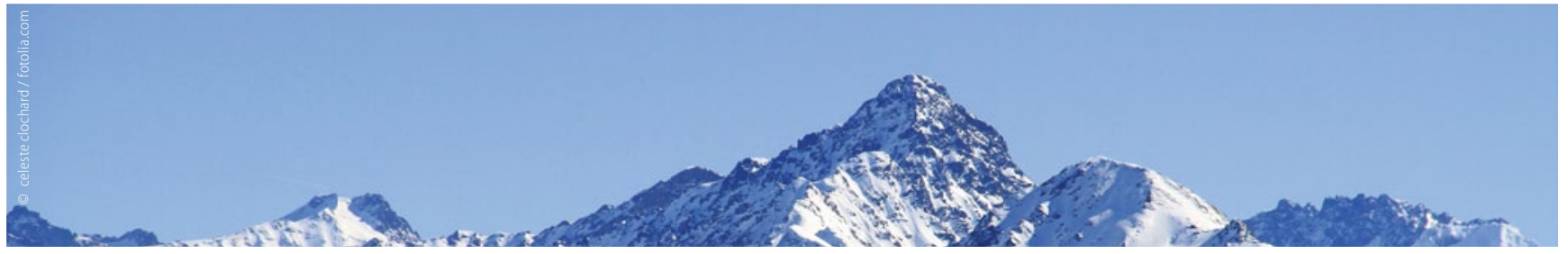

\section{Winterkongress in Davos}

\section{Schon gebucht?}

Vom 15. bis 20. Februar 2015 findet der. 47. Zahnärzte Winterkongress in Davos statt. Das umfangreiche Programm bietet ein interessantes Themenspektrum mit Workshops und Hands-onKursen. Bekannte Hochschullehrer und Praktiker präsentieren aus nahezu allen Gebieten der Zahnmedizin die neuesten wissenschaftlichen Erkenntnisse und ihre klinische Umsetzung. So stehen Seminare zur Endodontie, adhäsiven Zahnheilkunde, Oralchirurgie, Implantologie und ästhetischen Zahnmedizin zur Auswahl. Die angeschlossene Dentalausstellung bietet die Möglichkeit, sich ausführlich über neue Entwicklungen bzw. Bewährtes in der Dentalbranche zu informieren.
Dank des Engagements der Deutschen Apotheker- und Ärztebank spricht am Sonntag im Rahmen des Ökonomietages Dr. Roman Szeliga aus Wien über "Humor im Business - Das Begeisterungstool im Business!".

Der traditionelle Zahnärzte-Winterkongress findet in diesem Jahr letztmalig in Davos statt, ab 2016 ist das österreichische Ischgl Tagungsort.

Das Programm und weitere Informationen: Freier Verband Deutscher Zahnärzte e.V., E-mail: rs@fvdz.de, Telefon 02288557-55, Telefax 0228-34 5465 oder unter $w w w . f v d z . d e$.

\section{IDS 2015 vom 10. bis 14. März}

\section{Die globale dentale Branche zu Gast in Köln}

2100 Unternehmen aus 56 Ländern und eine Bruttoausstellungsfläche von mehr als 150.000 Quadratmetern: Die 36. Internationale Dental-Schau (IDS) behauptet sich mit neuem Ausstellerrekord und vergrößerter Hallenfläche als Leitmesse für die globale Dentalbranche. Vom 10. bis 14. März 2015 öffnet die weltgrößte Ausstellung für Zahnmedizin und Zahntechnik in Köln wieder ihre Tore.

$\mathrm{Zu}$ sehen sein wird eine breite Angebotspalette - vom zahnärztlichen über den zahntechnischen Bereich sowie Infektionsschutz und Wartung bis hin zu Dienstleistungen, Informations-, Kommunikations- und Organisationsmitteln.
Auch der Freie Verband Deutscher Zahnärzte (FVDZ) wird auf der IDS wieder dabei sein. Am verbandseigenen Stand gibt es neben allen wichtigen In-

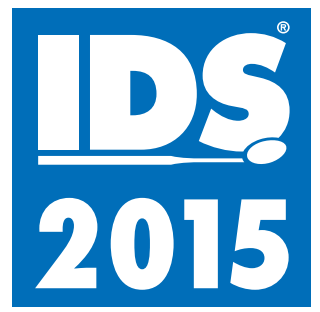
fos über den FVDZ und seine Standespolitik auch ein paar Überraschungen. Außerdem lädt der Verband, wie schon vor zwei Jahren, erneut Zahnmedizinstudenten zur IDS ein. Sie reisen in einer Sternfahrt aus verschiedenen UniStädten an. Mehr dazu lesen Sie in der DFZ-Februar-Ausgabe.

Alle Infos zur IDS gibt es unter www.ids-cologne.de. 